\title{
Algunas Notas sobre el servicio de información de la Monarquía Católica en el Mediterráneo en tiempos de Felipe II
}

\author{
David García HeRnán*
}

El apasionante tema de los sistemas de información en el ejército de la Monarquía Católica en el siglo XVI ha sido, desde siempre, una de las grandes cuestiones olvidadas por la Historiografía y, sin embargo, de gran importancia para desvelar el verdadero papel del ejército en la dinámica política de la Europa de aquel período. Algunos historiadores han llamado la atención en los últimos años sobre la importancia extraordinaria de la distancia y de los medios de comunicación ${ }^{1}-\mathrm{y}$ por consiguiente, de la transmisión de la información - en una época en que un correo podía tardar varias semanas desde Madrid a la mayoria de las capitales de Europa ${ }^{2}$. Pero en realidad, para el hombre de la era del “Concorde» le es dificil hoy hacerse una idea exacta del valor que tenían ciertas noticias en función del tiempo empleado en comunicarlas, sobre todo si no tenemos en cuenta que los respectivos servicios de información de las diferentes potencias europeas no contaban con otros medios que los estrictamente humanos: y de que de su labor pendía muchas veces de la suerte de las batallas.

Ante esta realidad, la Historiografía no ha dado todavía la respuesta a la altura que exigen nuestros ya sólidos conocimientos sobre otras cuestiones de temática paralela. En la actualidad no existe ninguna monografía

* Universidad Complutense. Madrid.

Como por ejemplo, el profesor Fernández Álvarez, quien en un relativamente reciente manual dedica, casi de un modo innovador, varias páginas a esias cuestiones. FEFNÁNDEZ ÁLVarez, M. y Díaz MedinA, A., Los Austrias Mayores y la culminación del imperio. Madrid 1987.

2 PARKER, G., Felipe II. Madrid 1978 
sobre los servicios de información y el espionaje en la época. Tan sólo disponemos de algunas obras generales sobre la historia del espionaje en general que, centradas en su mayoría en el caso francés, dedican algunas páginas a la evolución de los servicios de información ${ }^{3}$. Pero ni estos tratamientos sintéticos, ni las visiones de algunos artículos que han atendido a cuestiones particulares nos ofrecen un panorama lo suficientemente amplio como para un conocimiento profundo sobre el tema, toda vez que las obras clásicas sobre el ejército en el siglo XVI apenas contienen datos, ni mucho menos interpretaciones genéricas, sobre esta cuestión. Ni siquiera es totalmente justificable el hecho de la dificultad de la utilización de las fuentes históricas para este trabajo, que han estado y están, lógicamente, por la naturaleza secreta de mucha parte de esta documentación, ocultadas al historiador o con muy difícil acceso.

Sobre este sombrío panorama nuestra intención no es, ni mucho menos, ofrecer todas las claves explicativas y todos los hechos importantes del mundo del espionaje en la dimensión mediterránea de la política de Felipe II. Ahora bien, nos parece que con las notas que a continuación aportamos, ofrecemos alguna luz, y esperamos que tambíen surja alguna motivación sobre el estudio de este complejo tema ${ }^{4}$.

\section{LOS SISTEMAS DE INFORMACION}

Desde hacía mucho tiempo se venía considerando a la información como lo más necesario para organizar un plan de combate. Saber con qué efectivos contaba el enemigo era, en gran medida, garantizar el éxito. En el siglo XVI se consideraba que la astucia era la mejor estrategia, pero la principal parte de la astucia la constituía el secreto. El enemigo no debía conocer, entre otras muchas cosas, dónde se armaban las galeras. Además, era preciso reconocer lo más rápido posible a los espías del enemigo que estaban infiltrados en la armada. También se debía tener especial cuidado en no dar armas a los renegados que venían a servir en la armada, porque, sobre todo, en una hipotética escapada podían

3 Entre estas obras cabe destacar: el voluminoso trabajo, prácticamente de la propia época de Marana, G.P., L'Espion dans les cours des princes chretiens... Cologne 1696, 6 vols., sobre las informaciones realizadas por un enviado secreto del Imperio Otomano a las cortes europeas; Thompson, J.W.. y PADOVER, S.K., La diplomatie secrète politique en Europe de 1500 à 1815 . París 1938, con su capítulo III dedicado al espionaje en la época de Felipe II; y la obra general del español PAstor PeTIT, D., Historia del espionaje. San Cugat del Vallés 1967.

4 Quiero agradecer aquí la gran colaboración de Enrique García Hernán para la realización de este trabajo. Sin su preciosa ayuda posiblemente no hubiera llegado a manos del lector. 
Algunas notas sobre el servicio de información de la monarquía..

desvelar muchas informaciones que podían ser de alto valor para el enemigo. Todas estas cuestiones se tenían muy presentes por los altos mandos del ejército y la armada de la Monarquía Católica. Incluso había personajes, como Giovanni Battista Gesio, que subrayaban al moriarca la trascendente necesidad de la comunicación secreta de los negocios ${ }^{5}$. Por ello, tanto los grandes jefes del ejército y la política, como los mandos intermedios no escatimaban esfuerzos en recubrir a la información de los sistemas de control más sofisticados para la época.

Quizás el sistema de este tipo más empleado fuera el de las cifras. Cifrar las cartas era, normalmente, el sistema más seguro para pasar la información, y era generalmente utilizado y aprovechado por las más variadas instancias del sistema de defensa de la Monarquía Católica. La criptografía, o arte de escribir en signos convencionales, tendría en el siglo XVI una de las centurias de su edad de oro, hasta el punto de que en Francia se crearían complicadísimos sistemas en esta época que todavía incluso se emplean hoy ${ }^{6}$.

En general, se daban fundamentalmente dos tipos diferentes de cifra: hablada y escrita. A su vez, ésta última podía emitirse en otras formas diferentes: -en forma de palabras; -en forma de números y signos especiales; y -en forma mixta-, es decir con ambas conjuntamente. La hablada se utilizaba con más facilidad para relaciones de tipo personal, como, por ejemplo, la del secretario Eraso con el Cardenal de Burgos. Cuando querían hablar del comendador mayor de León se referian a él como Francisco de Bleda. También se utilizaba mucho esta cifra para la correspondencia entre navíos. Por ejemplo, cuando se referían a España la llamaban «doi belle sacarpe» ${ }^{7}$.

Con respecto a las cifras escritas, obviamente se renovaban los diferentes códigos cada cierto tiempo, con el fin de que el significado de las cifras tuviera más obstáculos para ser reconocido por demasiadas personas o por el propio enemigo ${ }^{8}$. De ellas, las cifras mixtas las solían

5 En una carta de Giovanni Battista Gesio a Felipe II, fechada en Madrid el 18 de Febrero de 1578, podemos leer estas significativas frases en este sentido: “... Tra le maggiori felicità che possa havere un gran Ré vi e il sapere e potere trattare con suoi ministri de negotij secreti e poner in esecutione le sue deliberationi senza ch'altri lo vengano a intendere, hora siano subditi, hora siano inimici, e tanto piu quando le spedetioni e li ministri son in parte lontane, in le quali bisogna trattare per mezzi di lettere, nuncil e avissi, perche da saper e poter far questo ne succedeno felici avenimenti nelli negotii...». British Library, Mss. Additional 28360. Le agradezco profundamente al profesor Fernando Bouza esta referencia.

6 Pastor Petit, D., Op. cit., pág. 391.

7 Archivo General de Simancas. Sección de Estado. 1548, 40. Cifras italianas.

${ }^{3}$ Van Durme ha estudiado precisamente muchos de estos sistemas de cifras que cambiaban periódicamente. 
utilizar los embajadores españoles con el rey y entre ellos mismos. El monarca mandaba la cifra por correo real, con la máxima garantía, acompañado normalmente de una carta al embajador ${ }^{9}$. Nos puede servir como ejemplo una carta del rey a Diego Guzmán de Silva, embajador en Venecia. Felipe II le dice que, puesto que la cifra general que se había estado usando era muy antigua, y puesto que algunos embajadores habían sido cambiados, se había decidido a cambiar de cifra, con el objeto de ser más efectivo y, sobre todo, seguro con el traspaso de información. Para ello se le enviaba una cifra general que se había de utilizar en el futuro, tanto en la correspondencia al rey como a cualquiera de sus ministros ${ }^{10}$.

Según este sistema, se podían comunicar entre ellos mismos pasándose todo tipo de información unos a otros con la misma clave.

\section{LA LABOR DE LOS ESPIAS}

Gran parte de los gastos de una armada iban dirigidos al sostenimiento de Ios espias. Su misión consistía fundamentalmente en conocer con exactifud el número, calidad y propósitos de la armada enemiga" Para con. seguir esta información poco a poco se fue creando un sistema complejo de espionaje. Una red de confidentes, contactos y espías se tejio entonces en torno a los puertos y ciudades de los turcos.

Mantener esa red suponía, como es lógico, mucho dinero. El que mejor pagera, más servicios de esta indole podria tener. Los nuncios del Papa solian tener mejor información, porque eran los que más pagaban, pero España. con ocasión de su interés por el Mediterráneo. pudo disponer de una red internacional de espionaje muy segura. El propio Felipe ll nos puede dar directamente una idea de la alta consideración que tenía a la labor del espionaje si atendemos a una de sus instrucciones mas explícitas en este sentido. Nos referimos a la instrucción a Don Sancho de Leyva en 1568 cuando le ordenó que se dispusieran de los medios económicos necesarios para esta misión. En sus propias palabras, le decia:

«Si huviere menester algún espía para tener aviso de lo que los ene. migos hazen, para podellos mejor ofender y guardar las galeras [...] os

Es interesante ver para este punto la publicación de Devos. J.P., Les chifres de Phelippe II (1555-1598) et du despacho universal durant lexvIl siècle. Bruxelles 1950

AGS, Estado 1501. 102. Felipe II a Diego Guzmán de Silva. El Escorial. 16 de julio 1571. Chescentio, B., Nautica Mediterranea. Roma 1602. Lib. 5. Cap. II. «Delle strategia navalis: 
damos la facultad para que podáis gastar en esto lo que conviniere, con yntervención de los dichos veedor y contador, y lo que así se gastare se libre y pague del dinero nuestro que oviere en las galeras, encargando a vos que os aya en ello moderación" ${ }^{12}$.

Después de la victoria de Lepanto, el servicio de espionaje europeo aumentó considerablemente, y con ello el trabajo de los secretarios, interrogadores, vigilantes, escribanos, etc. Fue tanto el trabajo, que los mismos embajadores preferían evitarse la dilación de cifrar una carta para que el destinatario la pudiera leer a tiempo. Un significativo y valioso ejemplo (en cuanto a la información que contiene) lo encontramos en el mismo comendador mayor de Castilla, Luis de Requeséns. Informó a Don Juan de Austria que los embajadores de Venecia le habían dicho que se tenía algún indicio y esperanza de que pudiera haber una rebelión en el mismo corazón del imperio turco al levantarse contra el sultán los jenízaros. Indudablemente, se trataba de una información valiosa que podría fundamentar posibilidades de lucha tanto en Levante como en África, pero, decía Requeséns: "no es cosa que doy mucho crédito, pero a podérsele dar sería de mucha importancia». Esta información no la envió en clave cifrada, "porque siendo el camino seguro de aquí a Meçina, no es bien dar travajo a los secretarios de V.E.; especialmente que los de acá no están oçiosos en poner lo mismo y otras cosas en zifra a España y otras partes" ${ }^{13}$.

También después de Lepanto se hizo un gran esfuerzo por coordinar los espías de Venecia y España. Don Juan de Austria escribió a Diego Guzmán de Silva que sería muy importante tener noticia de lo que hacía el enemigo, comunicándole que para ello había mandado por su parte a algunos hombres a Constantinopla, y que era muy necesario que se tratara con el Gobierno de Venecia que, por la suya, hiciera todas las diligencias posibles para saber los movimientos del enemigo y que se le fuera avisando diariamente sobre ello, "pues es de la importancia que se puede considerar: ${ }^{14}$. Otras veces, la iniciativa no salía sólo del propio Don Juan. En particular había mucho interés en que se enviaran a Constantinopla y a Argel espias de confianza para saber los movimientos que había en ambas partes ${ }^{15}$.

:2 [Arch]ivo de [Zab]álburu: Carpeta 184, 58 «Instrucción de Felipe II a Sancho de Leyva. $1568 "$.

AGS, Estado 1138, 33. Requeséns a Juan de Austria. Roma, 27 enero 1572

14 AGS, Estado 1501, 9. Don Juan de Austria a Diego Guzmán de Silva. Mesina, 12 de diciembre 1571

${ }_{15}$ AGS, Estado 1135, 134. Requeséns a Don Juan de Austria. Desde la galera sobre la torre del Faro, 15 noviembre 1571. 
Normalmente era el virrey, gobernador o embajador del lugar en cuestión quién enviaba al rey o al más interesado (que le tocara el asunto más directamente) las noticias recogidas de las diversas fuentes de información. Estas noticias podían ser de profesionales $y$, por tanto, con una paga por medio, o de personas ajenas al oficio, pero que por sus circunstancias personales, la información retenida por ellos podía ser valiosa. Se les pedía que informaran a cambio, lógicamente, de una recompensa. El embajador era considerado casi como un espía reconocido ${ }^{16}$, y para evitar complicaciones, los ministros del país solían neutralizar sus «extralimitaciones», y si no hubiera más remedio, se le expulsaba. Conocidos ejemplos de esta circunstancia son los casos de Gureau de Spes y Francés de Álava, expulsados de Inglaterra y Francia respectivamente ${ }^{17}$.

El sistema de comunicación oficial se hizo cada vez más complicado. Disponemos también, por ejemplo, de la información sobre los correos que disponía por vía oficial el embajador en Roma en 1579. En la minuciosa relación sobre el desempeño de este cargo se consigna expresamente que había correos ordinarios semanalmente desde la Ciudad Ełerna para Milán, Venecia, Génova, Alemania y Flandes; y quincenalmente para el Golfo de León en Francia. De Génova salían muchos correos para España, y desde allí se podían enviar los pliegos para el monarca, sin perjuicio de que cuando los asuntos lo requirieran se despachara correo propio y particular, tanto para el rey como para sus ministros ${ }^{18}$.

Sin embargo, no por este grado de complejidad dejó de ser esta comunicación oficial en muchos casos muy eficaz. La inmensa mayoría de las cartas iban cifradas, y, en algunas ocasiones incluso, la parte no cifrada contradecía la parte cifrada. El Cardenal Granvela, virrey de Nápoles, en una carta a Felipe II nos muestra esa labor eficiente de los espías y cómo, a su vez, debía ser disimulada. En una primera lectura consideraba que la función de los espías era poco eficaz, pues afirmaba con rotundidad y dureza que de los que se habian destinado a Levante no se había recibido ningún servicio de los muchos que tenían que intentar y sí se

is No en vano en las instrucciones para el desempeño de su cargo se le indicaba, como sucedió con el de Roma en 1579, que habría de informar siempre a Su Majestad de lo que sabía acerca de los cardenales y demás personajes de la corte pontificia, además de mantener con ellos las más exquisitas e intrincadas relaciones diplomáticas. [B]iblioteca [N]acional de [M]adrid. Sección de [M]anu[s]crito[s]. 10850.

17 Sobre los embajadores, ver especialmente la obra de FERnÁNDEZ Álvarez, M., Tres embajadores de Felipe // en Inglaterra. Madrid 1951

18 A Nápoles, e indirectamente a Sicilia, no se solía escribir con el correo ordinario de cada semana, porque había muchas estafetas que se despachaban entre particulares y que se podían aprovechar. B.N.M., Mss. 10860. Fol. 49 v. y 50 r. 
habían llevado mucho dinero ${ }^{19}$. Sin embargo, todo era para despistar a los servicios de información enemigos. Granvela tenía conocimiento exacto y preciso de la situación en Constantinopla, gracias, por ejemplo, a la información que recibió de Esteban López de Ávila, que permaneció preso en Constantinopla durante 13 años ${ }^{20}$. Lo que había escrito en su carta al monarca no iba cifrado, y la información cifrada eran, precisamente, noticias de espías de la Monarquía Hispánica ${ }^{21}$.

En efecto, la labor de estos espías era en ocasiones muy minuciosa y se traducía en extensos y precisos informes que permitían la formulación de estrategias con sólidos elementos de juicio. Incluso había militares que, embarcados en un largo viaje por dominios del enemigo, como el del capitán Antonio de Echavarri en 1575 por tierras de Bulgaria, elaboraban unas relaciones muy detalladas. En este caso concreto, después de hacer una descripción de las costumbres y disposición de los habitantes de estas tierras (a favor del rey de España y en contra del dominio turco), Echávarri exponía que estaba informado de que los habitantes de los reinos de Moldavia y Valaquia se sentían tan despreciados por el yugo otomano "que harían qualquier buen effecto contra el turco en casso que fuessen auissados para ello de parte de Su Mad.» ${ }^{22}$.

Afortunadamente, la documentación encontrada sobre este interesante pero complejo tema nos permite elaborar relaciones del personal que comprendía el servicio de información de la armada y, en general, de la Monarquía Hispánica; relaciones que incluso nos ofrecen la visión de las misiones específicas de cada espía y algunas de sus pautas de actuación. Podemos incluso hacer una distinción entre espías profesionales y espías que no lo son.

Entre los primeros destacaban sobre todo los que trabajaban en Levante y tenían como objetivo informar en España. Su labor se centraba en Constantinopla y su misión era obtener la mejor información posible. Entre ellos cabe citar a los siguientes:

- Adam de Franchis. Se trataba de un mercader, parece ser que suficientemente capacitado para el espionaje. Se le pagaban 500 ducados al año, en el último día de septiembre. Ordinariamente se pagaba a todos los espías el mismo día, una vez al año, y por adelantado. Para cobrar su remuneración (el sueldo preestablecido) el espía enviaba cartas, pero

\footnotetext{
AGS, Estado 1061. 2. Granvela a Felipe 1l, Nápoles, 31 enero 1572. AGS, Estado 1061, 31. "Relación de Estevan López de Ávila". 1572. AGS, Estado 1061. 2. Granvela a Felipe II, Nápoles, 31 enero 1572. Arch. Zab. Carp. 185-124.
} 
en muchas ocasiones se le pedía que repitiera la demanda por si se dispusiera que cambiara de lugar el espía. El enlace de este espía era Camilo Astrozi, un mercader que residía en Venecia, que había sustituido, por fallecimiento, al anterior enlace: García Hernández.

- Julio López o Tomás de Zornoza era un mismo personaje que ejercía su espionaje en Venecia. La información la pasaba vía Ragusa, pero cuando era muy importante la enviaba vía Corfú, siendo su destinatario el gobernador de Otranto. A este personaje se le había pagado hasta 1569 , pero además se le debían 300 ducados por lo que se gastó en correos y socorrer a algunos enlaces que iban a Constantinopla para traer información rápida.

-Aurelio de Santa Cruz. Conocido también con el nombre de Baptista Ferraro. Se trataba de otro mercader veneciano que tenía la misma paga que Adam, y sus enlaces eran también los mismos. Este personaje era el encargado de pagar a otros informadores turcos que había en Constantinopla. Solía cobrar este dinero con "cartas de pago dellos con firmas y sellos a la turquesca". Aurelio de Santa Cruz tenía por confidentes en Venecia a unos hermanos judíos llamados David Albundarem y Moisés. Para no descubrise, se tenía orden de que no hubiera ninguna comunicación entre Adam de Franchis y Aurelio de Santa Cruz, aunque se tenía un dispositivo secreto necesario para ponerlos en contaco en cualquier momento.

- Mustafá. Era un genovés renegado que ejercía su labor de espionaje como capitán de galera. Se le pagaban 300 ducados. Este capitán nunca escribía, por lo que su información oral la transmitía su contacto en Constantinopla: el espía Aurelio de Santa Cruz.

-Morataga. Considerado como el más valioso porque era coronel de 4.000 hombres con tropas de élite como los jenízaros y spachis. Además era "antiguo en el servicio". Cobraba también 300 ducados y tampoco escribía. Su contacto era Aurelio de Santa Cruz.

- Hamet Rais. «Hombre de calidad» que ejercía su labor también desde el cargo de capitán de galera con una paga de 100 ducados. No escribía y su enlace era igualmente Aurelio de Santa Cruz.

- Juan Sarimbal. Se trataba de un italiano que ejercía desde antiguo sin cobrar. Cuando en 1568 fue a España el jefe de información, Juan María Renzo, a organizar el servicio, Felipe II dispuso que este espía cobrara 150 ducados.

-Caín de Salín. También sirvió por amistad, pero este judío sería también incluido por Felipe II en la lista de pagados con 100 ducados de provisión. 
- Ambrosio Judize. Fue de los primeros espias en Constantinopla. En mayo de 1566 estuvo en Ragusa para cobrar las provisiones de todos los espías, pero, como habló demasiado, sospecharon sus propios compañeros de Constantinopla que si volvía les podía delatar, pues «es hombre que gusta demasiado del vino". Enseguida escribieron todos los espías para que no le pagaran y no le dejaran partir. Pero las cartas llegaron tarde, y ya había cobrado lo de todos. Con el dinero se fue a Venecia, donde se decía que había hablado otra vez más de la cuenta. En Venecia, aun sabiendo todo lo que pasaba, no se hizo nada para no llamar la atención del Senado de la república. Después se fue a Candía y de allí a Constantinopla. De los 1.000 ducados que llevaba para pagar a todos los espías solamente entregó 400 , alegando que en Roma le habían robado. Finalmente, ante este comportamiento, se le hizo ir desde Constantinopla a Ragusa, para «entretenerle o hazer lo que mejor paresciere», pero como había posibilidades de que renegara se había dispuesto que se le pagaran los dos años que se le debian.

Juan María Renzo, al que ya hemos mencionado, era el que más viajaba y el más importante. Incluso disponía de un cifra personal con Felipe II. Desde 1561 a 1572 hizo cuatro viajes a España y cinco a Italia. Se le pagaban 400 ducados.

Además había otros espías que fallecieron en servicio, por causas naturales, en esta época:

-Agustín Gilio. Tenía 600 ducados.

-El obispo de Nilo. Con 300 ducados de provisión.

-Ferrubey. Un renegado, sobrino del coronel de la isla cerca de Génova. Se le habían prometido 1.000 ducados de provisión, pero «llevándole la orden murió".

-Ambrosio Corbato. Con 300 ducados.

Los gastos anuales de todos estos espías eran de 2.300 ducados. Los puntos donde se recibían las cartas eran la isla de Mezo, Ragusa, Corfú, Zante, Cefalonia, Morea. Para que no se infiltraran espías del enemigo, cuando llegaban estos espías erar sometidos a un interregorario por parte del virrey de Sicilia. Para enviar la información, los espías se ponían en contacto con sus enlaces por medio de claves en las cartas. Si además se entregaba la carta en mano se usaba una contraseña; como por ejemplo: a su Majestad, Lamberto Grillo; a su Excelencia, Cesaro Alamano, Pietro GranDona, Hercule Piamontes; a Lope de MarDones, Teodoro Villanova. Adam de Franchis solía enviar la información obtenida por corros de Venecia a través de su enlace. Para que los enlaces se pusieran en contacto con los espías utilizaban otras claves. Por ejemplo, para ponerse en comunicación con Adam Franchis por vía de Venecia, se ponía en la 
carta: «Al Magnifico domino Aldamo di Franchis suo Honorando, etc.». Se firmaba Juan Sanrandino ${ }^{23}$. Cuando se utilizaba otro correo, como el de Ragusa, se ponía en la carta el nombre Ursino de Vergamo, «y quando ha de haver más de una letra otros nombres stravagantes». Era preciso guardar estas normas escrupulosamente y, según se decía, «tener mucho cuydado en esto, porque es la llave del secreto y podría subceder algún descuido con que se aclarase todo".

Aurelio de Santa Cruz solía escribir con la clave de «a su Excelencia Pietro GranDona». Cuando escribía por vía de Venecia iba firmada por Francisco Domiciano de Luca. Cuando la información pasaba por Ragusa iba dirigida a Baptista Ferrer ${ }^{24}$.

En cuanto a la información recibida por los no profesionales, es necesario singularizar primeramente el caso de Túnez. Carrillo de Quesada, gobernador de la Goleta, era el encargado de canalizar toda la información de Túnez y comunicarla a Felipe II, a Don Juan de Austria o a quien conviniera. Para conocer el tono y las pautas que seguía Quesada en sus informaciones, podemos ver los términos que empleaba para informar a Felipe II sobre un aspecto muy puntual. En ellos se ve la decidida intención por resaltar acontecimientos que pueden tener trascendencia dentro del panorama internacional:

«De una spía y dos renegados que han venido de Túnez he tenido aviso que están en Viçederta dos Galeotas de Argel que van en Constantinopla, y llevan dos cavalleros franceses embajadores de su rey, de que doi quenta al señor Don Juan de Austria, porque emportaría mucho tomar estas galeottas a saber el diseño del françés» ${ }^{25}$

El Gobernador de la Goleta recibía también información del Rey de Túnez, aliado de Felipe II, que le facilitaba el conocimiento, más o menos detallado, de lo que pasaba en aquella ciudad. Dicho rey se decía vasallo lealísimo del rey de España, y según declaraba a los cuatro vientos, en un tono un tanto melodramático, había perdido todo en su servicio: hacienda, mujeres, hijos, caballos, armas, piezas, pólvora, toda la renta de su estado, etc. Sin embargo, como también declaraba, estaba dispuesto a continuar en la lucha "porque yo soy su basallo y todo el bien que me berná no será sino de sus manos y de su favor» ${ }^{26}$.

23 AGS, Estado 1483, 123. "Memoria de los que dan avisos de las cosas de Levante a costa de S. M.».

24 AGS, Estado 1483, 123. "Memoria de los que dan avisos de las cosas de Levante a costa de S. M.».

25 AGS, Estado 1137, 20. Carrillo de Quesada al Rey. La Goleta, 19 de enero 1572.

26 AGS, Estado 1137, 163. Copia de una carta del Rey de Túnez a Carrillo de Quesada, de 14 de octubre de 1572. 
Dentro de los que trabajaban por facilitar toda suerte de información del enemigo de una manera no profesional también podemos incluir a los renegados y cristianos huidos del cautiverio ${ }^{27}$. Este grupo humano era un puente entre las dos culturas que sirvió como medio de comunicación en todos los sentidos; también en el militar. Todo esto se demuestra en el significativo caso de cinco renegados y cuatro cristianos que huyeron de Túnez, Bicerta y Susa hacia la Goleta. Durante el mes de marzo de 1572, mientras Don Juan está pensando acudir hacia Túnez y Bicerta, es informado de este caso ${ }^{28}$. Se trataba de una información precisa, muy buscada, a la vez que muy necesitada. El valor del testimonio se apoyaba en que eran testigos oculares de los hechos. La relación que escribieron resumía con todo lujo de detalles la situación, sobre todo militar, en Túnez; algo importantísimo, toda vez que sabemos que la empresa de Túnez y Bicerta era una de las que más se barajaban, concretamente la que llegó a preferir el rey de España para el próximo destino de la armada. Esta relación sería leída con sumo interés por el Duque de Terranova, quien decidió enviar una copia a Felipe II para que le sirviera de buen punto de referencia sobre la decisión que había que tomar ${ }^{29}$.

Particularmente importante en esta cuestión es también la actuación de Luis de Ansalone, un caso muy significativo digno de las más modernas e intrigantes películas de espionaje de nuestros días. La historia de este personaje arranca de su relación con Juan de Soto, secretario de don Juan de Austria. Este secretario presentó una carta credencial al Duque de Terranova, en la que decía que Luis de Ansalone se había ofrecido como voluntario para ir a Trípoli para ver en qué situación militar se encontraba esa plaza, cuáles eran las posibilidades de victoria para la armada española, y con qué fuerzas contaba para conseguirla. Soto advertía también a Don Juan sobre las cualidades excepcionales de Ansalone y, sobre todo, de su experiencia, por haber estado allí varias veces. Además era de gran confianza y, visto desde una forma práctica, en realidad nada se podría perder con su intervención y sí mucho que ganar.

En el memorial que dirigía sobre el caso a Don Juan de Austria, Soto tembién exponía algunas «reglas de oro" que había que guardar para la

27 Para el estudio psicológico de este grupo humano ver Bunes learRA, M. A., La imagen de los musulmanes y del norte de África en la España de los siglos XVI y XVII. Los caracteres de una hostilidad. Madrid 1989, Cap. III, págs. 139-184.

28 AGS, Estado 1137, 73. «Lo que han referido cinco renegados y cuatro cristianos que se han huido de Túnez, Biçerta y Susa a la Goleta, en el mes de março». 1572.

${ }_{29}$ AGS, Estado 1137, 169. Descifrada del Duque de Terranova a el Rey. Palermo 4 de noviembre 1572. 
feliz consecución de la operación. Ansola debía procurar entrar en contacto con sus amigos renegados para entrar «en algún trato que facilite aquelle empresa». En contrapartida, lo que pedía Ansalone era: - seis moros de Berbería de los que había en esa ciudad que hacía poco que se habian rescatado (lo que serviría de excusa para presentarse en Trípoli); - - licencia para llevar en su embarcación diversas mercancías para disimular la verdadera misión que llevaba y realizarla así con mayor comodidad.

Ante estas peticiones Don Juan decidió remitir el caso al Duque de Terranova. El secretario de Don Juan de Austria aconsejaba en el memorial que los moros no fueran personas de importancia, «de cuya libertad se puedan seguir inconvenientes» ${ }^{30}$. Al final se decidió utilizar los que podrían ser los valiosos servicios de Ansalone. El Duque de Terranova le había ordenado que hiciera una relación de la situación en Trípoli ${ }^{31}$, y puso manos a la obra.

Se fue a la capital norteafricana en marzo de 1571 con su barco, pan, vino, y otros alimentos para venderlos allí disfrazado y conseguir alguna información, pero, desgraciadamente, fue descubierto y encarcelado. No obstante, el 28 de septiembre de 1572 fue rescatado y el 20 del mes siguiente se encaminaba hacia Sicilia con un pequeño barco, donde llegó diez días más tarde.

Finalizando un intenso interrogatorio, como es lógico, sobre sus actividades, se sacó en claro los siguientes datos: -Se encontraban en la guarnición de Trípoli 300 arcabuceros; -150 jinetes de caballería mora mercenaria, y otros 400 que se encontraban sólo a dos días de distancia; - 400 moros de infantería mal armados; --100 piezas deartillería, de las cuales 40 eran móviles; -200 cántaros de pólvora; y, lo más importante y que más debía alegrar a los españoles, una gran penuria de vituallas. Además, le hicieron a Ansalone preguntas políticas, como si los moros estaban contentos del gobierno del Baja Mustafá, a lo que contestó que, por el contrario, estaban muy a disgusto. Además se le preguntó cuántos cristianos renegados había y con qué ánimo contra los cristianos. Ansalone respondió que 200 renegados, pero si viniera una armada de cristianos se alzarían contra los turcos. Además, informó que en Trípoli se encontraban 600 esclavos cristianos al servicio del Bajá y de Carlo Ferrato, un renegado genovés rico. En cuanto a la armada informó que había dos

30 AGS, Estado 1136, 125. Juan de Soto al Duque de Terranova. 8 diciembre 1571.

31 AGS, Estado 1137, 170. "Relatione di Ludovico Ansalone presa in Palermo a di doi di novembre 1572 per ordine del Illustrissimo Sr. duca di Terranova, Presidente di Sicilia». 
Algunas notas sobre el servicio de información de la monarquía...

galeras del Bajá y una Galeota de Carlo Ferrato. También le preguntaron qué sospechaban los turcos de la armada cristiana. Sobre esto no podía ofrecer muchos barcos, pero aclara que se encuentran, en una impresión general, con gran temor. Informó, asímismo, de la situación de la armada turca especificando que el 20 de septiembre llegó una galeota enviada por Luchalí para conocer las novedades ${ }^{32}$.

Por otra parte, los servicios de información que había en Constantinopla informaron a Don Juan de la situación militar de los turcos. Luchalí llegó a Constantinopla el 18 de diciembre con 27 galeras y 8 fustas. Una de las máximas preocupaciones de los turcos era conseguir 20.000 jenízaros nuevos. Por otro lado, en Constantinopla estaban en disposición de navegar 45 galeras, y en tierra había 11 galeras viejas. La situación de la armada turca se completaba con un total de 143 galeras desperdigadas por todo el Mediterráneo oriental y 8 fustas.

Por último, hay que decir que las fuerzas turcas también tenían sus propias fuentes de información, como lo demuestra nítidamente la extensa obra de G. P. Marana ${ }^{33}$. En 1572, por ejemplo, el Bajá había despachado a cuatro renegados para espiar las costas de la Cristiandad. Uno era un florentino de 35 años, otro napolitano, y dos genoveses ${ }^{34}$.

En definitiva, tanto en uno como en otro bando, el servicio de información formaba parte importante del dispositivo general militar en el Mediterráneo en la segunda mitad del siglo XVI. Un servicio de información que, con el tiempo, se irá haciendo cada vez más complicado, y en el que los espías jugaban un papel poco estudiado pero esencial.

32 AGS, Estado, 1137, 170. «Relatione di Ludovico Ansalone presa in Palermo a di doi di novembre 1572 per ordine del Ilustrissimo Sr. Duca di Terranova, Presidente di Sicilia».

33 Marana, G.P., Op. Cit..

34 AGS, Estado 1330, 135. «Por letras de Constantinopla de 5 de enero 1572". 